Brief Report

and pathologically from other tumors.

\section{CONFLICT OF INTEREST}

The authors have nothing to disclose.

\section{ORCID}

Hee Jae Park, https://orcid.org/0000-0002-3998-9042

Seung Pil Ham, https://orcid.org/0000-0002-4472-2043

Cheong Ha Woo, https://orcid.org/0000-0001-5538-7933

Mira Choi, https://orcid.org/0000-0003-2464-9675

Hai-Jin Park, https://orcid.org/0000-0002-9274-9371

\section{REFERENCES}

1. Chung EB, Enzinger FM. Fibroma of tendon sheath. Cancer 1979;44:1945-1954.

2. Millon SJ, Bush DC, Garbes AD. Fibroma of tendon sheath in the hand. J Hand Surg Am 1994;19:788-793.

3. Dal Cin P, Sciot R, De Smet L, Van den Berghe $H$. Translocation $2 ; 11$ in a fibroma of tendon sheath. Histopathology 1998;32:433-5.

4. Maluf HM, DeYoung BR, Swanson PE, Wick MR. Fibroma and giant cell tumor of tendon sheath: a comparative histological and immunohistological study. Mod Pathol 1995;8:155-159.

5. Gong LH, Liu WF, Ding Y, Geng YH, Sun XQ, Huang XY. Diagnosis and differential diagnosis of desmoplastic fibroblastoma by clinical, radiological, and histopathological analyses. Chin Med J (Engl) 2018;131:32-36.

\title{
A Case of Congenital Ectopic Nail Located on the Left 5 th Toe
}

\author{
Jun Hong Park, Jun Young Kim, Weon Ju Lee \\ Department of Dermatology, School of Medicine, Kyungpook National University, Kyungpook National University Hospital, Daegu, Korea
}

\section{Dear Editor:}

Ectopic nail is a condition involving the development of an additional and independent nail in an abnormal site. Few cases of congenital ectopic nail have been reported in the worldwide dermatological literature ${ }^{1}$. In Korea, a case of congenital ectopic nail was reported by Lew et al. ${ }^{2}$. In addition, a report on a Korean patient with posttraumatic ectopic nail was published in the Journal of Pediatric Dermatology in $2016^{3}$.
Herein, we describe a 62-year-old female patient with a congenital ectopic nail on the left 5th toe (Fig. 1A) that developed at birth. The nail had been felt tender for the last 2 years. There were no abnormal laboratory findings. Moreover, there were no abnormal bony deformities on radiological examination (Fig. 1B). She underwent surgery for removal of the congenital ectopic nail (Fig. 1A). Histopathologically, the congenital ectopic nail showed prominent hyperkeratosis (Fig. 2A). The expression of $\beta$ -

Received October 16, 2017, Revised February 3, 2018, Accepted for publication February 25, 2018

Corresponding author: Weon Ju Lee, Department of Dermatology, Kyungpook National University Hospital, 130 Dongdeok-ro, Jung-gu, Daegu 41944, Korea. Tel: 82-53-420-5838, Fax: 82-53-426-0770, E-mail: weonju@knu.ac.kr ORCID: https://orcid.org/0000-0001-5708-1305

This is an Open Access article distributed under the terms of the Creative Commons Attribution Non-Commercial License (http://creativecommons.org/ licenses/by-nc/4.0) which permits unrestricted non-commercial use, distribution, and reproduction in any medium, provided the original work is properly cited.

Copyright (C) The Korean Dermatological Association and The Korean Society for Investigative Dermatology 

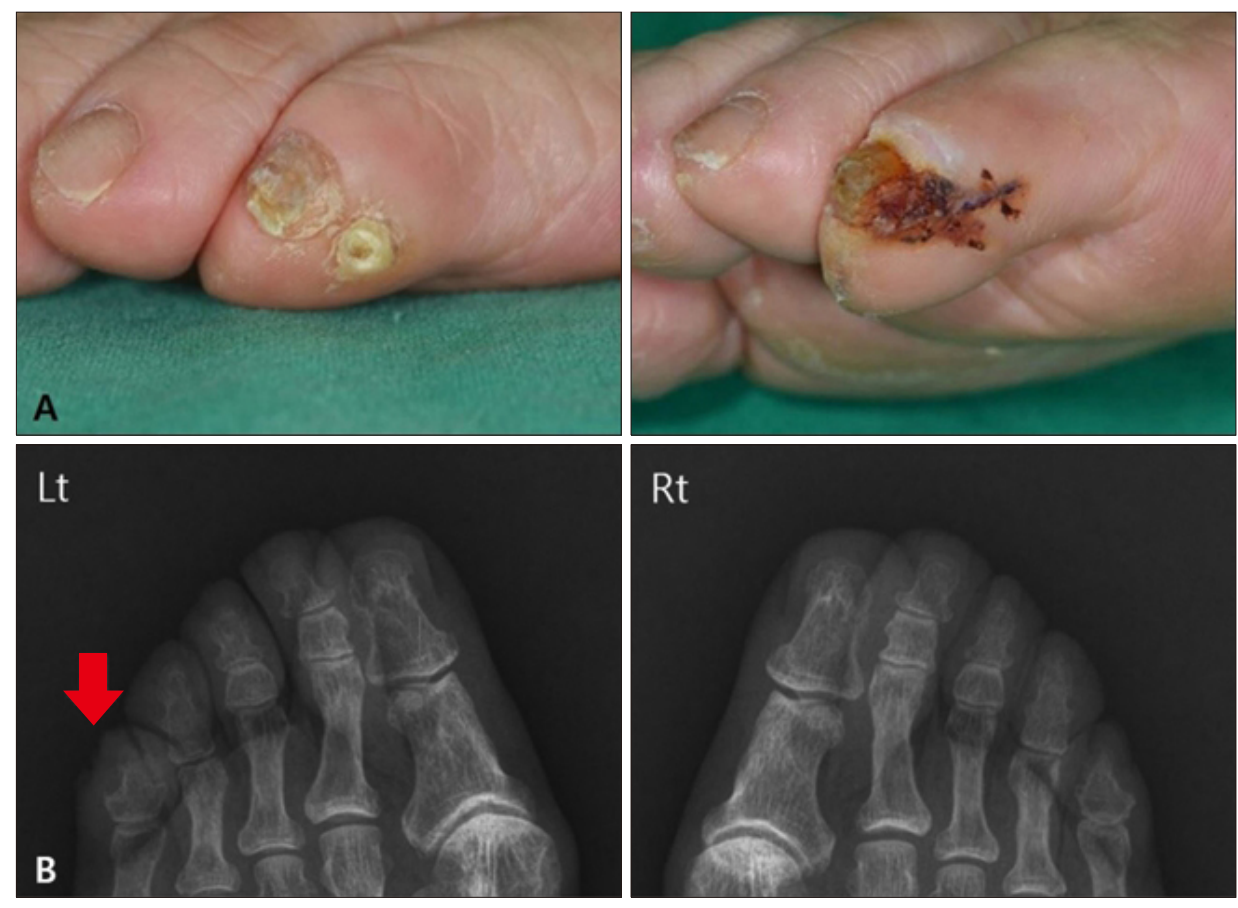

Fig. 1. (A) Congenital ectopic nail on the left 5th toe: preoperative and postoperative status. The patient's consent form about publishing all photographic materials was received. (B) No abnormality of bony structure of left 5 th distal phalanx.
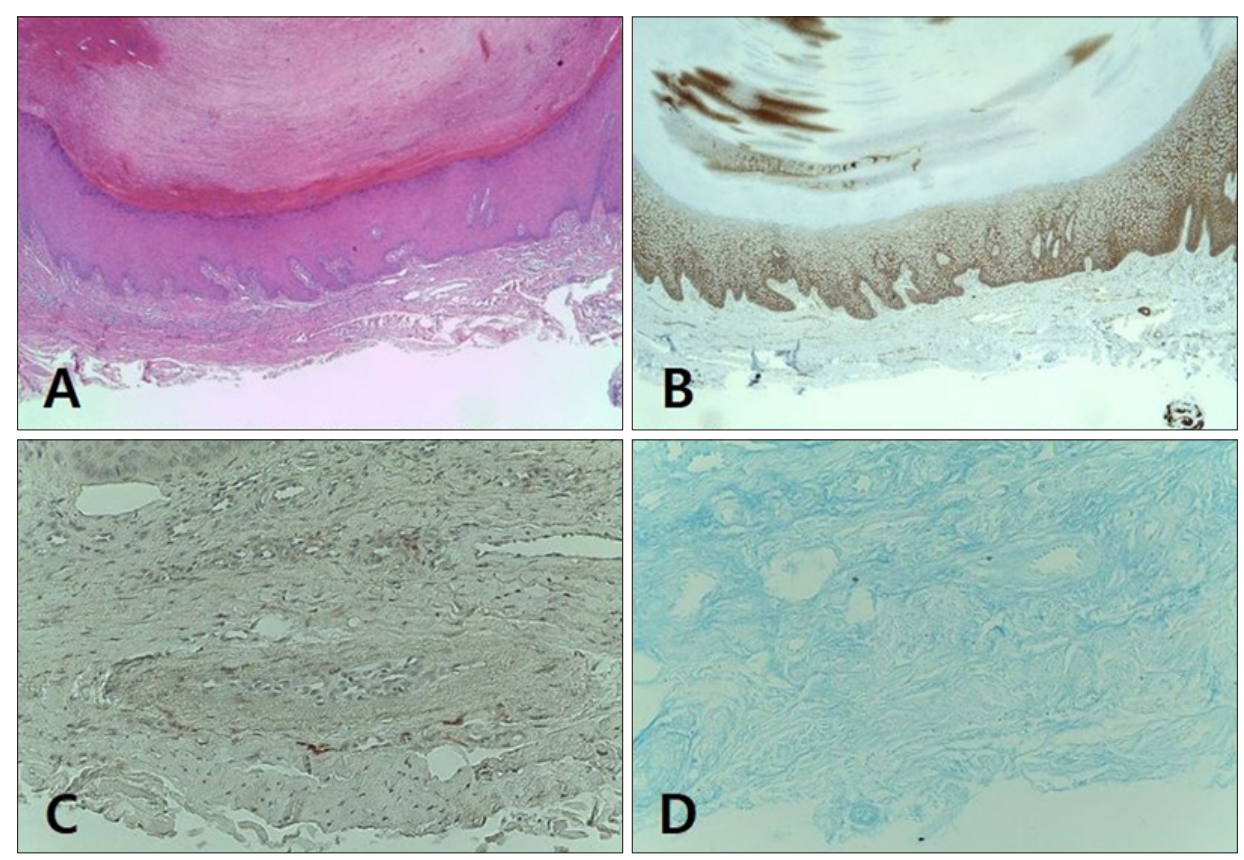

Fig. 2. (A) Hyperkeratosis on histopathological examination (H\&E, $\times 40$ ). (B) Expression of $\beta$-catenin on the epidermis under hyperkeratosis $(\beta$-catenin, $\times 40)$. (C) Expression of CD10 on the dermis under the ectopic nail (CD10, $\times 200)$. (D) Positive Alcian blue stain on the dermis under the ectopic nail (Alcian blue, $\times 200$ ). catenin was shown in the epidermal keratinocytes under the congenital ectopic nail (Fig. 2B). The dermis under the congenital ectopic nail showed CD10 expression (Fig. 2C), and the dermis turned bluish with the Alcian blue stain (Fig. 2D).

Ectopic nail, also known as onychoheterotopia, is a very rare disorder. It has been classified into an acquired type disorder caused by trauma and a genetically predisposed type disorder when there is no history of trauma. The pathogenesis of ectopic nail remains to be determined. However, various hypotheses, including the ectopic existence of a germ cell, rudimentary nail bed, and traumatic inoculation of onychocytes, have been proposed to explain the pathogenesis of ectopic nail ${ }^{4}$. Moreover, onychodermis for the specialized nail mesenchyme containing onychofibroblasts may serve an important function in the origin of ectopic nail ${ }^{5}$. The congenitally predisposed type is more common and can be attributed to digital deformity 
or bony malformation of the distal phalanx. Congenital ectopic nail can be associated with congenital palmar nail syndrome and Pierre Robin syndrome. Congenital ectopic nail usually develops on the fingers, whereas posttraumatic, acquired ectopic nail can occur on the fingers and toes. On histopathological examination, ectopic nail is characterized by a fully developed nail unit with an abnormal nail matrix. $\beta$-catenin, which plays an important role in hair and nail formation, is expressed in the nail matrix cells. The dermis under nail matrix can show the expression of CD10 and a positive stain with alcian blue. CD10, a cell surface metalloprotease, can be expressed in a variety of normal and neoplastic tissues, including the mesenchyme under the nail matrix and nail bed ${ }^{5}$. Ectopic nail can be confused with acquired digital fibroma, cutaneous horn, clavus, subungual exostosis, warts, rudimentary polydactyly, foreign body, hamartoma, and split nail deformity ${ }^{4}$. A fully developed nail unit on histopathological examination is important to diagnose ectopic nail. Ectopic nail can be removed through total surgical excision of the nail plate and nail matrix.

\section{CONFLICT OF INTEREST}

The authors have nothing to disclose.

\section{ORCID}

Jun Hong Park, https://orcid.org/0000-0003-1453-7370 Jun Young Kim, https://orcid.org/0000-0002-2999-1018 Weon Ju Lee, https://orcid.org/0000-0001-5708-1305

\section{REFERENCES}

1. Riaz F, Rashid RM, Khachemoune A. Onychoheterotopia: pathogenesis, presentation, and management of ectopic nail. J Am Acad Dermatol 2011;64:161-166.

2. Lew BL, Park JH, Kim NI. Congenital ectopic toenail: a case report and review of the literature. Ann Dermatol 2004;16: 109-112.

3. Kong TS, Lee YC, Son SJ, Lee JH, Han TY. Subungual posttraumatic ectopic nail. Pediatr Dermatol 2016;33:e170171.

4. Ena P, Ena L, Ferrari M, Mazzarello V. Ectopic foot nails: clinical and dermoscopic features, treatment and outcome in 20 cases. Dermatology 2015;231:298-303.

5. Lee DY, Park JH, Shin HT, Yang JM, Jang KT, Kwon GY, et al. The presence and localization of onychodermis (specialized nail mesenchyme) containing onychofibroblasts in the nail unit: a morphological and immunohistochemical study. Histopathology 2012;61:123-130. 